\title{
PENINGKATAN PENGETAHUAN IBU TENTANG UPAYA PREVENTIF PENYAKIT ISPA PADA BALITA MELALUI FOCUS GROUP DISCUSSION (FGD)
}

\author{
Etika Purnama Sari \\ Akademi Keperawatan Adi Husada Surabaya \\ etikaps@gmail.com
}

\begin{abstract}
ABSTRAK
Balita mudah terkena penyakit ISPA karena tubuh balita masih rentan terhadap penyakit infeksi. Banyak ibu yang tidak tahu tentang pencegahan penyakit ISPA. Metode FGD (focus group discussion) dapat digunakan untuk meningkatkan pengetahuan. Tujuan dari penelitian ini adalah menjelaskan peningkatan pengetahuan ibu melalui FGD. Desain penelitian adalah pra eksperimental one group pra post test design. Variabel yang diteliti adalah tingkat pengetahuan ibu. Sampel yang digunakan adalah ibu yang memiliki balita di wilayah RT 3 RW 1 Kelurahan Sidotopo Wetan Kecamatan Kenjeran sebanyak 13 orang. Pengambilan data menggunakan kuesioner. Berdasarkan hasil uji Wilcoxon Sign Rank Test dengan tingkat signifikansi $\alpha<0,05$, didapatkan nilai $\mathrm{p}=0,002$ yang berarti ada peningkatan pengetahuan ibu melalui FGD. Adanya peningkatan dikarenakan faktor pendidikan, usia, pengalaman serta proses diskusi dalam FGD. Bagi para ibu harus tetap mengakses informasi tentang preventif ISPA dalam berbagai media.
\end{abstract}

Kata kunci: Focus Grup Discussion, Pengetahuan, ISPA

\begin{abstract}
Children with age 12-60 months are susceptible to ISPA due to their body was still susceptible to infectious diseases. Many mother do not know about the prevention of ISPA. FGD (focus group discussion) can be used to increase their knowledge. The aim of this study is to explain the increasing mother's knowledge through the FGD. The study design was a pre-experimental one-group pre-post test design. The variables studied were the level of mother's knowledge. The samples used were mothers with babies aged 12-60 months as many as 30 people. Data was collected by questioner. Based on the test results of the Wilcoxon Sign Rank Test with a significance level of $\alpha<0,05, p$ value $=$ $p=0,002$ which means there is the increasing mother's knowledge through the FGD. The increasing knowledge due to factors of education, age, experience, and the discussion process in the FGD. For mother must still access information about preventive ISPA in a variety of media.
\end{abstract}

Keywords: Focus Grup Discussion, knowledge, ISPA

\section{PENDAHULUAN}

Infeksi Saluran Pernafasan Akut (ISPA) dikenal sebagai salah satu penyebab kematian utama pada bayi dan anak balita di negara berkembang ${ }^{1}$. Hal tersebut dikarenakan sistem pertahanan tubuh anak masih rendah. Masih banyak ibu yang tidak tahu apa itu penyakit ISPA, bagaimana pencegahannya, sehingga masih banyak ditemukan balita dengan kasus ISPA $^{2}$. Tingkat pengetahuan yang rendah itu maka untuk meningkatkan dengan memberikan penyuluhan dengan beberapa metode, salah satunya adalah FGD (focus group discussion ${ }^{3}$.

ISPA menyebabkan empat dari 15 juta kematian pada anak berusia di bawah lima tahun pada setiap tahunnya, sebanyak dua per tiga kematian tersebut adalah bayi. Tingkat mortalitas akibat ISPA pada bayi, anak dan orang lanjut usia tergolong tinggi terutama di negara-negara dengan pendapatan per kapita rendah dan menengah. ISPA juga merupakan salah satu penyebab utama konsultasi atau rawat inap di sarana pelayanan kesehatan terutama pada bagian perawatan anak. Di Indonesia diperkirakan 3-6 kali pertahun terjadi penyakit batuk pilek pada balita ${ }^{1}$. Pada tahun 2011 terdapat 123 balita yang berobat karena ISPA. Hal ini dilatarbelakangi karena faktor tingkat pengetahuan $\mathrm{ibu}^{4}$. Berdasarkan hasil survei pada bulan Mei 2016 di RT 1 RW 3 kelurahan Sidotopo Wetan kecamatan Kenjeran banyak ibu yang memiliki balita mengatakan masih sering mengalami ISPA berulang.

Faktor yang mempengaruhi pengetahuan adalah pendidikan ibu yang sangat rendah, serta kurangnya informasi/ media massa yang 
didapatkan ibu, sosial dan budaya, lingkungan yang tidak bersih dapat memicu timbulnya penyakit ispa, kurangnya pengalaman ibu terhadap penanganan penyakit ISPA, dan usia ibu dapat menentukan tingkat pemahaman pengetahuan tentang penyakit ISPA ${ }^{4}$ (Nursalam, 2005). ISPA dapat berlanjut menjadi pnemonia sering terjadi pada anakanak terutama apabila terdapat gizi kurang dan dikombinasi dengan keadaan lingkungan yang tidak sehat ${ }^{2}$.

Banyak metode penyuluhan yang dapat dilakukan untuk meningkatkan pengetahuan, salah satunya melalui diskusi ${ }^{3}$. Focus Group Discussion (FGD) adalah bentuk diskusi yang didesain untuk memunculkan informasi mengenai keinginan, kebutuhan, sudut pandang, kepercayaan dan pengalaman yang dikehendaki peserta $^{5}$.

Tujuan dari penelitian ini adalah untuk menjelaskan peningkatan pengetahuan ibu melalui FGD terhadap upaya preventif ISPA.

\section{METODE PENELITIAN}

Desain penelitian ini adalah pra eksperimental one group pra post test design.. Waktu penelitian pada bulan Mei 2016. Tempat penelitian di wilayah Kelurahan Sidotopo Wetan Kecamatan Kenjeran Surabaya.

Populasi dalam penelitian ini adalah semua ibu yang memiliki balita di wilayah RT 3 RW 1 Kelurahan Sidotopo Wetan Kecamatan Kenjeran Surabaya. Pengambilan sampel dengan menggunakan purposif sampling dengan menentukan kriteria yaitu pernah mengalami ISPA lebih dari sekali sebanyak 13 orang.

FGD dilakukan satu kali berdasarkan waktu yang disepakati dengan responden. Pengumpulan data tingkat pengetahuan dengan kuesioner, dilakukan sebelum FGD dan sesudah FGD. Analisa data dengan menggunakan uji statistik Wilcoxon Sign Rank Test.

HASIL

Data Umum

Tabel 1 Karakteristik Responden

\begin{tabular}{llll}
\hline No. & Karakteristik & $\mathrm{n}$ & $\%$ \\
\hline \multirow{2}{*}{1} & Usia & & \\
\cline { 2 - 4 } & $19-24$ & 3 & 23 \\
\cline { 2 - 4 } & $25-30$ & 4 & 31 \\
\cline { 2 - 4 } & $31-36$ & 6 & 46 \\
\cline { 2 - 4 } & Total & 13 & 100 \\
\hline 2 & Pendidikan & & \\
\cline { 2 - 4 } & Tidak sekolah & 1 & 8 \\
\cline { 2 - 4 } & SD & 2 & 15 \\
\cline { 2 - 3 } & SMP & 1 & 8 \\
\cline { 2 - 3 } & &
\end{tabular}

\begin{tabular}{llll}
\hline & SMA & 9 & 69 \\
\cline { 2 - 3 } & PT & 0 & 0 \\
\cline { 2 - 4 } & Total & 13 & 100 \\
\hline 3 & Pekerjaan & & \\
\cline { 2 - 4 } & IRT & 3 & 23 \\
\cline { 2 - 3 } & Swasta & 7 & 54 \\
\hline Wiraswasta & 1 & 8 \\
\hline PNS & 2 & 15 \\
\hline Total & 13 & 100 \\
\hline
\end{tabular}

Berdasarkan tabel 1 responden hampir sebagian besar berusia 31-36 tahun (46\%), sebagian besar berpendidikan SMA (69\%), dan sebagian besar bekerja di swasta (54\%).

Tabel 1 Data Khusus Responden di RT 3 RW 1 Kelurahan Sidotopo Wetan Kecamatan Kenjeran Surabaya Mei 2016

\begin{tabular}{lllll}
\hline Pengetahuan & \multicolumn{4}{c}{ Frekuensi } \\
\cline { 2 - 5 } & Pre & $\%$ & Post & $\%$ \\
\cline { 2 - 5 } Kurang & 7 & 54 & 0 & 0 \\
Cukup & 6 & 46 & 0 & 0 \\
Baik & 0 & 0 & 13 & 100 \\
Total & 13 & 100 & 13 & 100 \\
\hline
\end{tabular}

Wilcoxon sign rank testp $=0,002(\alpha<0,05)$

Berdasarkan tabel 2 tingkat pengetahuan pasien sebelum dilakukan FGD sebagian besar kurang (54\%), setelah dilakukan FGD meningkat menjadi baik (100\%). Hasil uji Wilcoxon Sign Rank Test menunjukkan nilai $\mathrm{p}=$ 0,002 .

\section{PEMBAHASAN}

Berdasarkan hasil uji statistik dengan menggunakan Wilcoxon Sign Rank Test menunjukkan nilai $\mathrm{p}=0,002$ dimana tingkat signifikansi $\alpha=0,05$ yang berarti ada peningkatan pengetahuan ibu melalui FGD.

Ada 2 faktor yang mempengaruhi pengetahuan, yaitu faktor internal dan eksternal. Faktor internal yaitu pendidikan, pekerjaan, umur. Faktor eksternal meliputi lingkungan, social budaya, dan informasi ${ }^{6}$. Focus Group Discussion (FGD) atau diskusi kelompok terarah merupakan bentuk data kegiatan pengumpulan melalui wawancara kelompok dan pembahasan dalam kelompok sebagai alat/media paling umum digunakan dalam metode PRA maupun ZOPP. FGD diikuti oleh para peserta yang idealnya terdiri dari 7-11 orang. Kelompok tersebut harus cukup kecil agar memungkinkan setiap individu mendapat kesempatan mengeluarkan pendapatnya, sekaligus agar cukup memperoleh pandangan 
dari anggota kelompok yang bervariasi. Dalam jumlah relatif terbatas ini diharapkan juga penggalian masalah melalui diskusi atau pembahasan kelompok dapat dilakukan secara relatif lebih memadai. ${ }^{7}$

Peningkatan pengetahuan ibu tentang upaya preventif penyakit ISPA dapat dikarenakan oleh tingkat pendidikan ibu yang sebagian besar SMA dimana semakin tinggi pendidikan seseorang semakin mudah menyerap informasi yang didapat. Selain pendidikan peningkatan tersebut dikarenakan oleh pengalaman ibu yang sudah pernah merawat anaknya yang mengalami ISPA, semakin banyak pengalaman maka semakin tahu bagaimana cara mencegahnya. Saat seseorang melakukan diskusi (FGD) maka akan timbul proses dua arah sehingga akan lebih fokus dan mudah menyerap informasi.

\section{SIMPULAN}

Berdasarkan hasil uji statistik ada peningkatan pengetahuan ibu melalui FGD tentang upaya preventif ISPA.

\section{SARAN}

Bagi ibu tetap harus meningkatkan pengetahuan tentang pencegahan ISPA dengan mengakses informasi dari berbagai media.Penelitian selanjutnya diharapkan memakai kelompok kontrol dan menambah jumlah sampel.

\section{DAFTAR PUSTAKA}

1. WHO. 2007. Pencegahan dan Pengendalian Infeksi Saluran Pernapasan Akut (ISPA) yang Cenderung Menjadi Epidemi dan Pandemi di Fasilitas Pelayanan Kesehatan. http: //www.who.int/csr/resources/publications/WHO CDS_EPR_2007_8b ahasa.pdf. Tanggal Akses 21 Maret 2016. Jam akses 10.00 WIB.

2. Nelson. 2006. Pedoman Pemberantasan Penyakit ISPA. Jakarta.

3. Gilstrap, Martin. 2007. Kelebihan dan Kekurangan Metode. Jakarta : Tiara Wacana.

4. Darwanti. 2012. Upaya Dalam Mengatasi Infeksi Saluran Pernafasan Akut (ISPA). Jakarta.

5. Paramita, Astridya dan Lusi Kristiana. 2013.Teknik Focus Group Discussiondalam Penelitian Kualitatif. http://ejournal.litbang.depkes.go.id/index.php/hsr /article/view/3301. Tanggal akses 22 Maret 2016. Jam akses 16.00 WIB.

6. Dewi dan Wawan. 2010. Teori dan Pengukuran Sikap dan Perilaku Manusia. Yogyakarta: Nuha Medika.

7. Indrizal, Edi. 2014. Diskusi Kelompok Terarah Focus Group Discussion (FGD) (Prinsip-Prinsip dan Langkah Pelaksanaan Lapangan). Jurnal Antropologi. Vol 16, no 1. 